\title{
ESCALA DE DESENVOLVIMENTO MOTOR: AVALIAÇÃO DO PROJETO PIRACEMA DA UNIVERSIDADE DE SANTA CRUZ DO SUL - UNISC, RS
}

Sandra Mara Mayer ${ }^{1}$, Laudemiro Volmar da Cunha Trindade $^{2}$, Heloisa Elesbão ${ }^{3}$, Lawrence Azambuja ${ }^{1}$, Tainá Laisa Werberich ${ }^{1}$

1Universidade de Santa Cruz do Sul - UNISC, Santa Cruz do Sul, RS, Brasil.

${ }^{2}$ Associação de Pais e Amigos dos Excepcionais de Santa Cruz do Sul - APAE/SCS, Santa Cruz do Sul, RS, Brasil.

${ }^{3}$ Universidade Federal de Santa Maria - UFSM, Santa Maria, RS, Brasil.

E-mail: smmayer@unisc.br

Acesso DOI: http://dx.doi.org/10.34059/ciejop.2019v28i1-11

Introdução: O Projeto Piracema é uma parceria da Universidade de Santa Cruz do Sul (UNISC) e a Associação de Pais e Amigos dos Excepcionais de Santa Cruz do Sul (APAE/SCS). Atende 34 pessoas com deficiência que possuem diversas patologias, por meio de intervenções aquáticas que ocorrem três vezes por semana na piscina pedagógica da UNISC. As atividades propostas em aula são: jogos recreativos, adaptação ao meio liquido, exercícios de fortalecimento e relaxamento muscular, estimulação a coordenação motora ampla e fina, exercícios de respiração e socialização. De modo a avaliar a progressão dos alunos durante o período de intervenção em meio aquático são realizadas avaliações que tem por objetivo identificar o nível de desenvolvimento motor dos participantes. Diante disso, o presente trabalho tem por objetivo avaliar a idade motora dos alunos com os testes de Escala de Desenvolvimento Motor (EDM) de Rosa Neto. Metodologia: Foram avaliados 14 alunos, com idade entre 9 e 41 anos, sendo 10 do sexo feminino e 4 do sexo masculino. Os protocolos aplicados foram os de testes que avaliam especificamente o Esquema Corporal/Rapidez, Organização Espacial, Linguagem/Organização Temporal, Motricidade Fina e Global, e Equilíbrio. Após somou-se a idade motora de cada um desses aspectos (em meses) e realizou-se a divisão por 6, obtendo-se então a idade motora geral. Resultados: Através resultados obtidos, verificamos que na motricidade fina os sujeitos apresentaram $4,4 \pm 2,3$ anos, na motricidade global $4,0 \pm 1,9$ anos, no equilíbrio $3,0 \pm 1,5$ anos, no esquema corporal/rapidez $3,6 \pm 1,2$ anos, na organização espacial $4,1 \pm 1,8$ anos $e$ Linguagem/Organização Temporal $3,3 \pm 1,7$ anos. Conclusão: Os sujeitos dessa pesquisa apresentam padrão motor inferior a sua idade cronológica. A partir dos resultados serão feitas adequações no planejamento e organização dos exercícios proporcionados com o intuito de proporcionar uma melhora em suas habilidades motoras e por consequência em sua idade motora geral.

Palavras-chave: Desenvolvimento Motor. Pessoas com Deficiência. 